\title{
Anomalous summer climate in China influenced by the tropical Indo-Pacific Oceans
}

\author{
Hengyi Weng • Guoxiong Wu Yimin Liu • \\ Swadhin K. Behera • Toshio Yamagata
}

Received: 2 July 2009/Accepted: 28 August 2009/Published online: 2 October 2009

(c) The Author(s) 2009. This article is published with open access at Springerlink.com

\begin{abstract}
Possible influences of three coupled oceanatmosphere phenomena in the Indo-Pacific Oceans, El Niño, El Niño Modoki and the Indian Ocean Dipole (IOD), on summer climate in China are studied based on data analysis for the summers of 1951-2007. Partial correlation/ regression analysis is used to find the influence paths through the related anomalous mid- and low-level tropospheric circulations over the oceanic region and East Eurasia, including the western North Pacific summer monsoon (WNPSM). Among the three phenomena, El Niño Modoki has the strongest relationship with the WNPSM. When two or three phenomena coexist with either positive or negative phase, the influences exerted by one phenomenon on summer climate in different regions of China may be enhanced or weakened by other phenomena. In 1994 when both El Niño Modoki and IOD are prominent without El Niño, a strong WNPSM is associated with severe flooding in southern China and severe drought in the Yangtze River Valley (YRV). The $500 \mathrm{hPa}$ high systems over China are responsible for heat waves in most parts of China. In 1983 when a strong negative phase of El Niño Modoki is accompanied by moderate El Niño and IOD, a weak WNPSM is associated with severe flooding in the YRV and
\end{abstract}

H. Weng $(\bowtie) \cdot$ G. Wu · Y. Liu

LASG, Institute of Atmospheric Physics,

Chinese Academy of Sciences, 100029 Beijing, China

e-mail: weng@lasg.iap.ac.cn; hengyi_weng@yahoo.com

S. K. Behera · T. Yamagata

Application Laboratory, JAMSTEC,

Yokohama 236-0001, Japan

T. Yamagata

Graduate School of Science, University of Tokyo,

Tokyo 113-0033, Japan severe drought in southern China. The $500 \mathrm{hPa}$ low systems over China are responsible for the cold summer in the YRV and northeastern China. For rainfall, the influence path seems largely through the low-level tropospheric circulations including the WNPSM. For temperature, the influence path seems largely through the mid-level tropospheric circulations over East Eurasia/western North Pacific Ocean.

Keywords El Niño - El Niño Modoki · IOD ·

Summer monsoon $\cdot$ Summer climate in China

\section{Introduction}

The summer season is the time when extreme flooding and droughts frequently occur in China. Some droughts due to lack of rainfall are exacerbated by concurrent heat waves. Since the weather conditions in China were first recorded in history, China has experienced flooding/drought disasters almost every year. Since 1951, on average, the flooding (drought) in each year affects 9.8 (22.5) million hectares of cultivable land, ${ }^{1}$ which is about $8 \%(18.5 \%)$ of the 121.8 million hectares of cultivable land in China based on the 2006 statistics. $^{2}$ The disastrous flooding/drought results in more and more direct and indirect economic loss due to China's fast economy growth in recent decades. To explore various factors influencing China's climate and to mitigate the loss due to disastrous flooding/drought are of socioeconomic importance to China's sustainable development.

One such factor influencing China's climate is the seasurface temperature (SST) distribution in the tropical IndoPacific Oceans, which has been much studied in the past

\footnotetext{
${ }^{1}$ http://www.gov.cn/zxft/ft25/wzzxgd.htm.

${ }^{2}$ http://www.mlr.gov.cn/xwdt/jrxw/200704/t20070412_80256htm.
} 
two decades (e.g., Huang and Wu 1989; Wu and Liu 1992, 1995; Wu and Meng 1998; Zhang et al. 1999; Lau and Weng 2001; Chan and Zhou 2005; Gao et al. 2006). The along-equator SST gradient plays an important role in the intensity and longitudinal position of the Walker Circulation (Bjerknes 1969; Lindzen and Nigam 1987) that has large influence on precipitation in the Pacific Rim countries. The tropical Indo-Pacific Oceans are important sources of energy driving the large-scale atmospheric circulations that are related to the variation in moisture transport to China. Thus, the amount of the moist air supplied to China from the Indo-Pacific Oceans is very likely related to some coupled ocean-atmosphere phenomena in this broad oceanic region. Here we provide a review on three ocean-atmosphere phenomena in the IndoPacific Oceans, since their climate impacts on China during summer season will be the focus of this study.

In the tropical Pacific, the most studied coupled oceanatmosphere phenomenon over the past few decades is the so-called "El Niño", or the canonical El Niño, which exhibits a dipole SST anomaly (SSTA) pattern with anomalous warming in the tropical eastern Pacific and cooling in the tropical western Pacific (e.g., Rasmusson and Carpenter 1982). Countless research papers aimed at understanding and predicting El Niño as well as its climate impacts have been published (e.g., Wallace et al. 1998; Trenberth et al. 2002). However, the definition of El Niño itself has been changing. The Niño3 index, ${ }^{3}$ which has been widely used to identify El Niño events, has missed some events with warming in the tropical central Pacific. To include these events, the Niño3.4 index was then suggested to define El Niño events (Trenberth 1997). On 30 September 2003, the (US) National Oceanic and Atmospheric Administration (NOAA) announced a consensus for El Niño index and definition. ${ }^{4}$ The new El Niño definition is based on the area-mean SSTA in the Niño3.4 region. On 10 February 2005, such a consensus on El Niño definition was reached among three North American countries. ${ }^{5}$ By using this Niño3.4 index as El Niño definition, some additional El Niño events, which have been missed by using the Niño3 index, have been identified. Since these additional El Niño events are related to the warming near the Date Line, which exert different climate impacts from those with warming in the Niño3 region,

\footnotetext{
3 The SST indices for Niño1 +2 , Niño3, Niño3.4, and Niño4 are defined by NOAA as: Niño $1+2\left(0^{\circ}-10^{\circ} \mathrm{S}, 90^{\circ}-80^{\circ} \mathrm{W}\right)$, Niño 3 $\left(5^{\circ} \mathrm{N}-5^{\circ} \mathrm{S}, 150^{\circ}-90^{\circ} \mathrm{W}\right)$, Niño $4\left(5^{\circ} \mathrm{N}-5^{\circ} \mathrm{S}, 160^{\circ} \mathrm{E}-150^{\circ} \mathrm{W}\right)$, and Niño $3.4\left(5^{\circ} \mathrm{N}-5^{\circ} \mathrm{S}, \quad 170^{\circ}-120^{\circ} \mathrm{W}\right)$ (http://www.cpc.ncep.noaa.gov/data/ indices/). The El Niño and La El Niña events identified by NOAA are given at http://www.cpc.noaa.gov/products/analysis_monitoring/ ensostuff/ensoyears.shtml.

${ }^{4}$ http://www.noaanews.noaa.gov/stories/s2095.htm.

5 http://www.weather.gov/pa/fstories/2005/0205/fs10feb2005b.php.
}

Larkin and Harrison (2005) named these additional El Niño seasons "Dateline" El Niño. Thus, the new definition by using the Niño3.4 index has mixed up two types of El Niño events: the events with warming in the tropical eastern Pacific (mainly in the Niño3 region) and those with warming in the tropical central Pacific (mainly in the Niño4 region).

Recent studies indicated that there are two types of El Niño events in the tropical Pacific, even though the definitions of these "two types" given by different authors are somewhat different. Ashok et al. (2007) and Weng et al. (2007) proposed the concept of El Niño Modoki (or pseudo El Niño) and used observational data analysis to show that it is a coupled ocean-atmosphere phenomenon with the sea surface warming in the tropical central Pacific and cooling in both eastern and western tropical Pacific. Spatially, this phenomenon is different from the canonical El Niño with warming in the tropical eastern Pacific (Niño3 region) and cooling in the tropical western Pacific. Temporally, El Niño Modoki is dominated by decadal timescales and the canonical El Niño is dominated by interannual timescales (Weng et al. 2007). Their distinctive spatial and temporal ocean-atmosphere characteristics as well as their different climate impacts imply that El Niño Modoki and the canonical El Niño are two different phenomena. They do not necessarily appear as two stages of an ENSO cycle.

Similar two types of ENSO with warming in the eastern and central tropical Pacific, respectively, are also proposed in other studies based on area-mean SSTA. For example, $\mathrm{Yu}$ and Kao (2007) and Kao and Yu (2009) proposed an eastern-Pacific (EP) type and a central Pacific (CP) type of ENSO. Kug et al. (2009) proposed the cold tongue (CT) El Niño and warm pool (WP) El Niño. Despite different terms used by these authors to describe "two types" of El Niño, all these authors have clearly shown that the warming in the tropical central Pacific should be studied separately from the warming in the tropical eastern Pacific. Some application studies about different impacts of two types of El Niño on the regional climate in data analyses and numerical modeling also support the idea that two different types of phenomena in the tropical Pacific Ocean should be studied separately (Wang and Hendon 2007; Chang et al. 2008; Weng et al. 2009; Ashok et al. 2009; Taschetto and England 2009; Taschetto et al. 2009; Kim et al. 2009). The Bureau of Meteorology in Australia has improved the lead time for its seasonal regional climate prediction by separating El Niño Modoki from El Niño in their Predictive Ocean Atmosphere Model for Australia (H. Hendon, private communication).

In the Indian Ocean, the SSTA pattern exerts important influences on the tropical atmospheric circulation and the climate in Asian countries (e.g., Wu and Liu 1992). Anomalous zonal SSTA gradient in the tropical Indian 
Ocean influences not only the Indian monsoon, but also the East Asian/western North Pacific monsoon. The Indian Ocean Dipole (IOD) coined as well as identified in 1999 (Saji et al. 1999; Behera et al. 1999) could be seen as a measure of the zonal SSTA gradient in the tropical Indian Ocean. Although the difference of the SSTA between the two poles of IOD is smaller than that between the two poles of El Niño, the zonal SSTA gradient in the tropical Indian Ocean may be comparable with that in the tropical Pacific due to the fact that the zonal scale of the tropical Indian Ocean is much smaller than that of the tropical Pacific Ocean. The IOD has been associated with the summer rainfall anomaly in China (e.g., Li and Mu 2001; Xiao et al. 2002; Guan and Yamagata 2003; Guan et al. 2003).

Observational and modeling studies have shown that some IOD events occur with El Niño events. During such cases, both the tropical western Pacific Ocean and the tropical eastern Indian Ocean are anomalously cold. However, other IOD events occur without El Niño events or even with La Nina events (Behera et al. 2008). Possible links between IOD and El Niño Modoki have also been recently studied (Tozuka et al. 2008). In order to discuss regional climate influences of these phenomena, it is important to identify individual and combined influences (e.g., Behera et al. 2006).

Here we study and compare possible influences of the above three ocean-atmosphere phenomena in the tropical Indo-Pacific Oceans (i.e., El Niño, El Niño Modoki and IOD) together with their combined influences on summer climate in China. Those influences may occur through variations of the large-scale atmospheric circulations in the East Eurasian/western North Pacific region, including the western North Pacific summer monsoon (WNPSM). Other climate factors may also have important influences on China's summer climate. However, we only focus on these three phenomena in the present study.

Section 2 introduces the data and methods. Section 3 compares the summer climate in China that may be influenced by one of the El Niño, El Niño Modoki and IOD phenomena. Section 4 explores large-scale tropospheric circulation patterns related to the three tropical phenomena, and compares the relationships of the three phenomena with WNPSM. Section 5 provides case studies to explore possible interactive influences of these phenomena on China's summer climate. Finally, Sect. 6 presents discussions and concluding remarks of this study.

\section{Data and methods}

The analysis period for this study is the boreal summers composed of June-July-August during the period of 19512007. The SST used here is from the Hadley Centre Global
Sea Ice and Sea Surface Temperature (HadISST) monthly data (Rayner et al. 2003). The NCEP/NCAR Reanalysis (Kalnay et al. 1996) monthly data are used to analyze atmospheric circulations that bridge the tropical SSTA patterns with the climate in China. We also use the monthly in situ precipitation and temperature data at 160 stations in China. All the monthly anomalies are departures from their respective mean values averaged over the data period. The monthly anomaly data are then averaged over the three summer months to get the summer seasonal anomaly data, except for the summer seasonal rainfall anomaly data that are the sums of the monthly rainfall anomalies of June, July and August.

The normalized monthly and summer seasonal time series of the three indices that represent the three phenomena in the Indo-Pacific Oceans are shown in Figs. 1 and 2, respectively. The (canonical) El Niño is quantified by the Niño3 index (or simply "Niño3"), defined by the mean SSTA averaged over the region $\left(150^{\circ}-90^{\circ} \mathrm{W}, 5^{\circ} \mathrm{S}-\right.$ $5^{\circ} \mathrm{N}$ ), as shown by the box in Fig. 3a. The El Niño Modoki is quantified by the El Niño Modoki index (or simply "EMI"), defined as

$\mathrm{EMI}=[\mathrm{SSTA}]_{\mathrm{C}}-0.5[\mathrm{SSTA}]_{\mathrm{E}}-0.5[\mathrm{SSTA}]_{\mathrm{W}} ;$

where the square bracket with a subscript represents the area-mean SSTA, averaged over one of the three regions specified as the central $\left(\mathrm{C}: 165^{\circ} \mathrm{E}-140^{\circ} \mathrm{W}, 10^{\circ} \mathrm{S}-10^{\circ} \mathrm{N}\right)$, eastern $\left(\mathrm{E}: 110^{\circ}-70^{\circ} \mathrm{W}, 15^{\circ} \mathrm{S}-5^{\circ} \mathrm{N}\right)$, and western $(\mathrm{W}$ : $125^{\circ}-145^{\circ} \mathrm{E}, 10^{\circ} \mathrm{S}-20^{\circ} \mathrm{N}$ ), as shown by the three boxes in Fig. 3b. The Indian Ocean Dipole phenomenon is quantified by the Indian Ocean Dipole Mode Index (or simply "IOD"), defined as the difference of the area-mean SSTA between the western region $\left(50^{\circ}-70^{\circ} \mathrm{E}, 10^{\circ} \mathrm{S}-10^{\circ} \mathrm{N}\right)$ and the southeastern region $\left(90^{\circ}-110^{\circ} \mathrm{E}, 10^{\circ} \mathrm{S}-\mathrm{Eq}\right)$ of the tropical Indian Ocean (Saji et al. 1999; Yamagata et al. 2004), as shown by the two boxes in Fig. 3c.

Figure 1 shows that although El Niño events generally peak in the winter season, there may be apparent El Niño characteristics in the tropical Pacific SSTA during the preceding or following summer season (e.g., the summers of 1972, 1983, and 1997). Similarly, although IOD events often peak in the fall season, some events may have already developed pronounced IOD characteristics in the tropical Indian Ocean in the preceding summer season (e.g., 1961, 1972, 1994, and 1997). Thus, in a summer season, it is possible that the three phenomena may occur individually or jointly. Because the atmosphere responds quickly to tropical SSTA's change, here we focus on the summer climate anomalies in China associated with the presence of at least one of the three phenomena in the same summer season. Thus, the summer seasonal mean indices shown in Fig. 2 will be used for analyses in this work. 
Fig. 1 Normalized monthly time series of the three indices: Niño3 (shaded), EMI (red line), and IOD (black line)
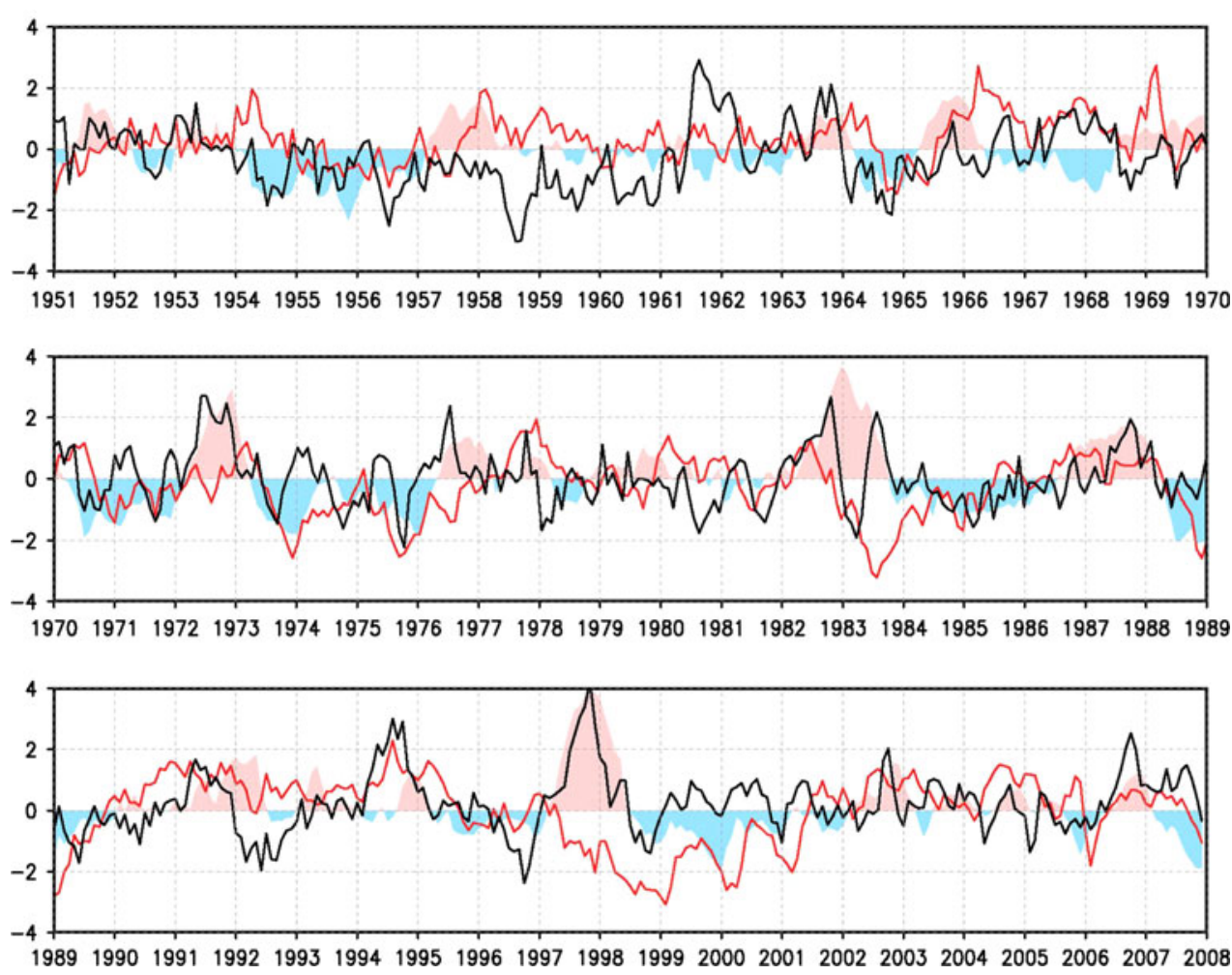

The linear correlation coefficients between EMI and Niño3 (IOD) is $-0.11(-0.03)$, showing that EMI has little correlation with both Niño3 and IOD. However, the positive correlation between Niño3 and IOD (0.45) is statistically significant. In order to find possible linear relationships between each of the three phenomena and the related climate variables in China, we use the partial correlation/regression analysis, instead of the regular correlation/regression analysis, to remove the influence from other two phenomena when they coexist. By doing so, we are able to use these results to reconstruct the part of the rainfall/temperature anomalies that are related to the three tropical phenomena based on the three indices for a given summer.

The statistical significance tests for partial correlation coefficients in the time domain are performed using the two-tailed Student's $t$ test. The degrees of freedom used for such a test is 54 for a time series having 57 summers. $^{6}$ The correlation coefficients that are significant at the 80, 90, 95 and $99 \%$ levels are $0.18,0.22,0.26$ and 0.34 , respectively. Our focus is on the comparison between different impacts of the three tropical phenomena on the summer climate in China, which could be understood dynamically through teleconnection paths. The statistical significance given here is for reference only.

For a given summer, the significance test of a spatial correlation coefficient function (SCCF) between the

\footnotetext{
${ }^{6}$ http://www2.chass.ncsu.edu/garson/pa765/partialr.htm.
}

observed and reconstructed rainfall/temperature anomaly patterns in China based on the three phenomena, depends on the number of spatial degrees of freedom of the timevarying rainfall/temperature anomaly fields. Following Bretherton et al. (1999), we first perform the empirical orthogonal function (EOF) analysis of the rainfall and temperature anomaly fields, respectively, to determine their effective numbers of spatial degrees of freedom $\left(N_{\mathrm{ef}}^{*}\right)$ of these fields. It is defined as the number of EOF modes that account for $90 \%$ of the overall variance, which is 13 for rainfall and 10 for temperature, respectively. The degrees of freedom used in the Student's $t$ test for a SCCF in the analysis is $N_{\mathrm{ef}}^{*}-1$. Thus, the criteria of the SCCF between the observed and reconstructed anomaly fields which are statistically significant at the $80,90,95$ and $99 \%$ levels are $0.37,0.45,0.53$ and 0.65 for rainfall, and $0.42,0.52,0.60$ and 0.72 for temperature, respectively.

The SCCF between the observed and reconstructed anomaly patterns is a measure of their coherence in anomaly sign but not necessarily in magnitude. In order to know how good a reconstructed anomaly pattern is compared to the observed flooding/drought or warm/cold anomaly pattern, the magnitude of the reconstructed rainfall or temperature anomalies should also be estimated. Thus, in this study, we also use the percentage of explained variance, $P$, to show how close a reconstructed spatial rainfall/temperature anomaly pattern could explain its corresponding observed rainfall/temperature anomaly pattern. It is defined as 

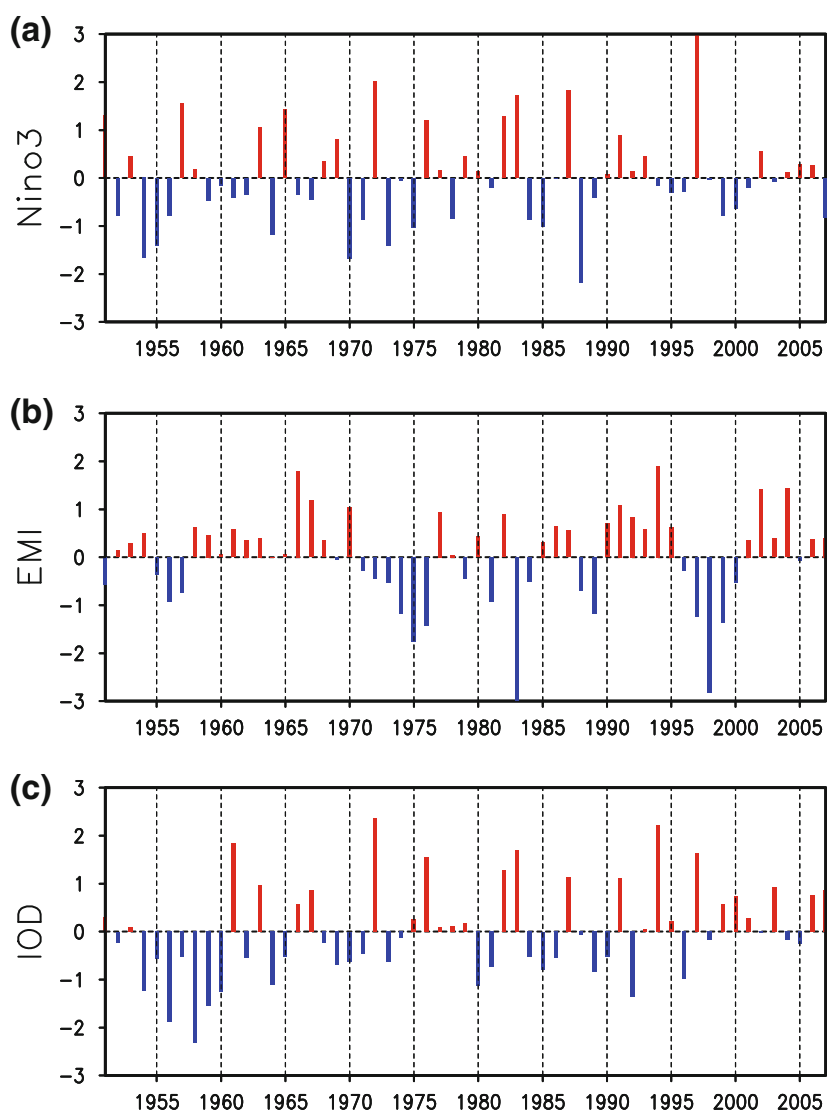

Fig. 2 Normalized summer mean time series of the three indices: a Niño3, b EMI, and $\mathbf{c}$ IOD. The standard deviation for Niño3, EMI and IOD are $0.757,0.410$ and $0.365^{\circ} \mathrm{C}$, respectively

$P=1-\sum_{x}\left[\mathrm{Obs}-\sum_{j}\left(I_{j} \times S_{j}\right)\right]_{x}^{2} / \sum_{x}(\mathrm{Obs})_{x}^{2}$,

where Obs represents observed rainfall/temperature anomaly, $I_{j}$ is the $j$ th index $(j=1$ : Niño3; $j=2$ : EMI; $j=3$ : IOD) shown in Fig. 2 for a given summer, and $S_{j}$ is the spatial partial linear regression pattern of the observed rainfall/temperature anomaly against $I_{j}$ as shown in Fig. 4. The summation over $j$ indicates that the reconstruction is based on all the three indices, which combines the influences of the three phenomena when they coexist. The summation over $x$ indicates that $P$ is estimated at each station and then summed up over all the 160 stations $(x=1,160)$ or the so-called "all-China". The term in the square bracket on the right hand of (2) is the variance error. In the limit, when the variance error is zero, the reconstruction is perfect so that $P=1$. When the variance error reaches to 1 or larger, $P$ is set to zero. The closer the value of $P$ to unity, the better the approximation of a reconstructed rainfall/temperature anomaly pattern is compared to the corresponding observed pattern (Lau and
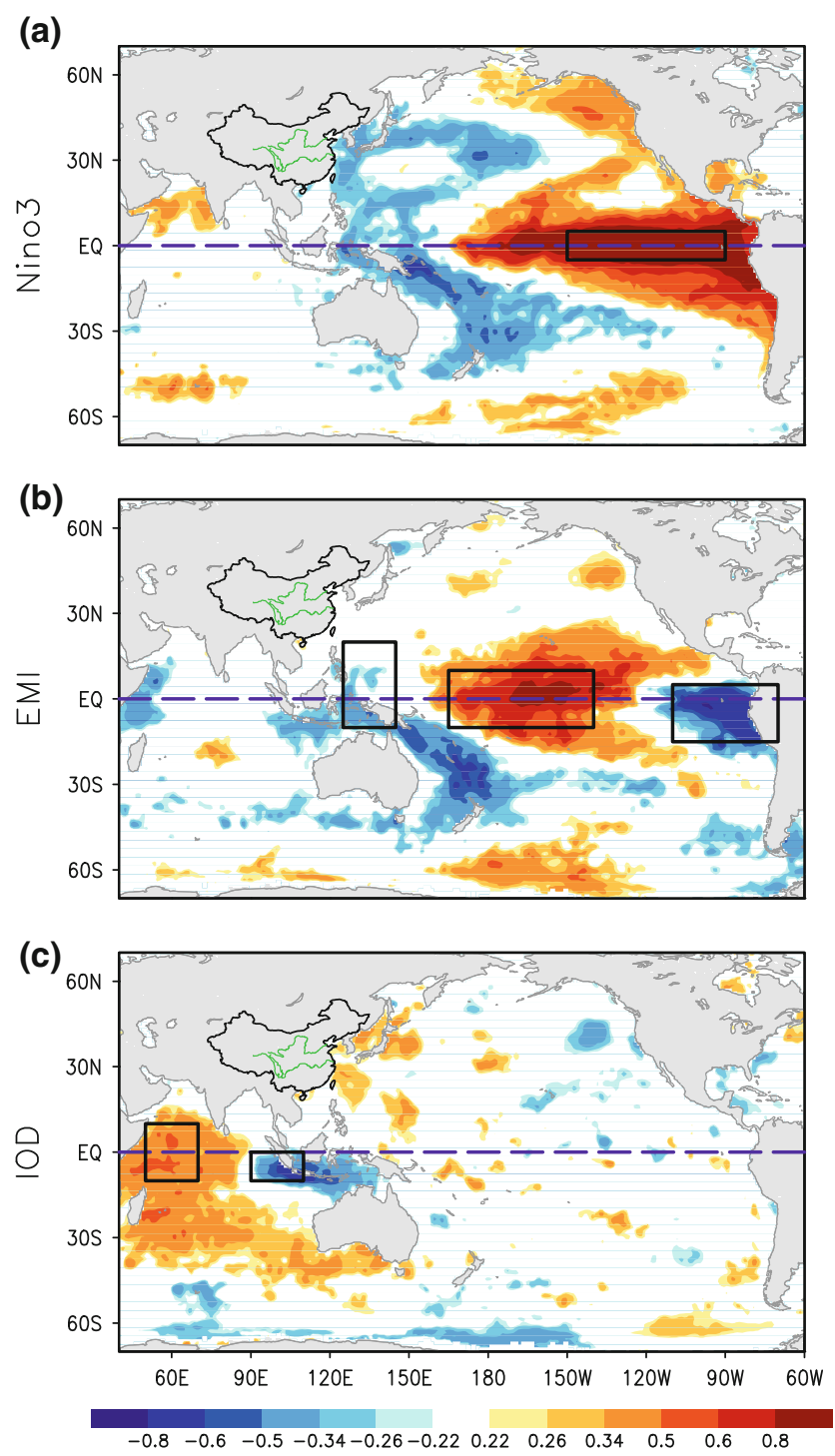

Fig. 3 Partial correlation patterns of SSTA for a Niño3, b EMI, and c IOD

Weng 2001). Note that the explained variance $(P)$ of the observed anomaly pattern by a reconstructed anomaly pattern is not simply equal to the square of the SCCF between the two.

For simplicity, the terms "summer", "warm (cold)", "wet (dry)", and "high (low)" used in the text correspond to "boreal summer", "warmer (colder) than normal" for temperature anomalies, "wetter (drier) than normal" for rainfall anomalies, and "higher (lower) than normal" for $500 \mathrm{hPa}$ geopotential height anomalies, respectively. Here the term "normal" for a given variable is the "climatological mean" of the variable during the analysis period. The description for spatial pattern in the following discussion is with respect to a positive phase of the corresponding SSTA index if not specified otherwise. 
Fig. 4 Partial regression patterns of rainfall (left panels) and temperature (right panels) anomalies in China with the three indices. The upper, middle, and lower panels are for Niño3, EMI, and IOD, respectively. The southern and northern rivers (green) are the Yangtze River and the Huanghe River, respectively
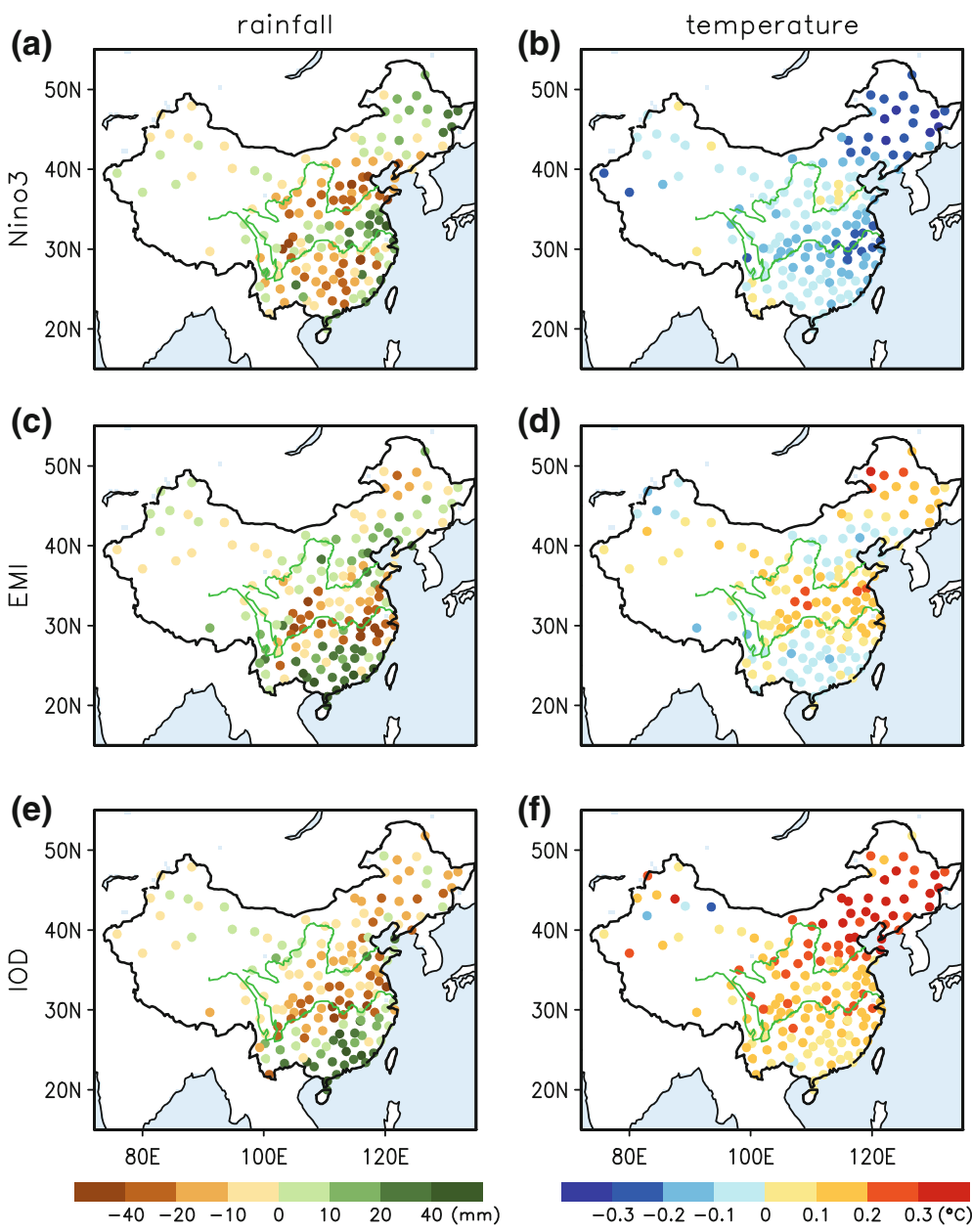

\section{SSTA features and related anomalous summer climate in China}

The temporal features of the three phenomena in the summer season during the data period are shown in Fig. 2. The spatial features of the SSTA patterns related to the three phenomena are shown in Fig. $3 \mathrm{a}-\mathrm{c}$, which are presented by the partial correlation coefficients between the three indices in Fig. 2 and the SSTA field for the data period. The main spatial features for summer El Niño and El Niño Modoki during the data period are similar to those shown in Weng et al. (2007) that are for the boreal summers of 1979-2005. The main spatial features of IOD are similar to those shown in previous studies for IOD (e.g., Saji et al. 1999; Yamagata et al. 2004). The clear separation among the three SSTA patterns in Fig. 3a-c, based on the partial correlation analysis, demonstrates the independent influences of the three phenomena represented by SSTA if only one of the three phenomena exists. However, we find mixed contributions to SSTA from two or three of these phenomena if we apply the regular correlation analysis (figures not shown). Such a simple statistical analysis does not necessarily mean the existence of dynamical/ physical relationship between these phenomena (Yamagata et al. 2004; Behera et al. 2006).

Figure 4 shows the rainfall and temperature changes associated with a $1 \mathrm{SD}$ change in each one of the indices. That is, when only one of the three phenomena is assumed to occur and its anomaly changes by $1 \mathrm{SD}$ in the tropical Indo-Pacific Oceans, the anomaly of the summer climate in China related to this phenomenon might occur.

During El Niño summers, the rainfall anomaly pattern in Fig. $4 \mathrm{a}$ is similar to many of the previous studies about El Niño influence on the summer rainfall anomaly in China (e.g., Ju and Slingo 1995; Lau and Weng 2001). A wet band is likely to appear in the Yangtze River valley (YRV), especially in the lower reach of the Yangtze River and the Huaihe River. The regions to the north and south of this wet band are likely to be dry, especially in the lower reach of the Huanghe River in northern China. There are also secondary wet regions in northeastern China and the coastal region of southeastern China. For temperature (Fig. 4b), most of China is cold during El Niño summers, especially in the YRV and northeastern China. The cold 
summers in northeastern China during El Niño events have been an important research subject because of their severe impacts on the agriculture in that region (e.g., Wang and Wu 1997).

During El Niño Modoki summers, for rainfall (Fig. 4c), the most likely wet region is southern China, with a secondary wet region in northern China near $40^{\circ} \mathrm{N}$ to the east of $108^{\circ} \mathrm{E}$. In contrast to the situation during El Niño, the YRV is likely to be the driest region in China during El Niño Modoki, with a secondary dry region in the northern part of northeastern China. For temperature (Fig. 4d), northeastern China and the region between the Yangtze River and the Huanghe River are warm, with cold bands in both southern and northern China.

During IOD summers, for rainfall (Fig. 4e), southeastern China is very likely to be wet with the wettest area in the coastal region, and most of the remaining China is dry with the driest region in the YRV. For temperature (Fig. 4f), most of China is warm, especially northern and northeastern China.

Figure 4 shows the climate anomaly patterns that might occur when only one of the three phenomena in the IndoPacific Oceans is assumed to occur. However, the real world is much more complicated than those presented in these patterns due to the coexistence of two or three tropical phenomena, let alone other factors that also influence China's climate have been left out in this study. Possible influence of the coexistence of two or three of these tropical phenomena on China's summer climate will be discussed in Sect. 5.

\section{Atmospheric circulation patterns and the related WNPSM}

The impact paths from the coupled ocean-atmosphere phenomena in the tropical Indo-Pacific Oceans to the summer climate in China have been considered to be the large-scale atmospheric circulations over the East Eurasia/ western North Pacific region (e.g., Tao and Chen 1987; Wang and Yasunari 1994; Chang et al. 2000; Wu et al. 2000; Liu et al. 2002; Wang et al. 2003; Weng et al. 2004; Ding and Chan 2005). Here, we also examine influence paths from the three tropical phenomena to anomalous summer climate conditions in China through the related mid- and low-level tropospheric circulations, including the WNPSM.

Figure 5 presents the partial linear regression patterns of the $500 \mathrm{hPa}$ geopotential height anomalies and the $850 \mathrm{hPa}$ horizontal wind anomalies associated with the three SSTA indices. To quantitatively compare the relationship between each one of the three phenomena and the WNPSM, we use the WNPSM index (Wang and Fan 1999)
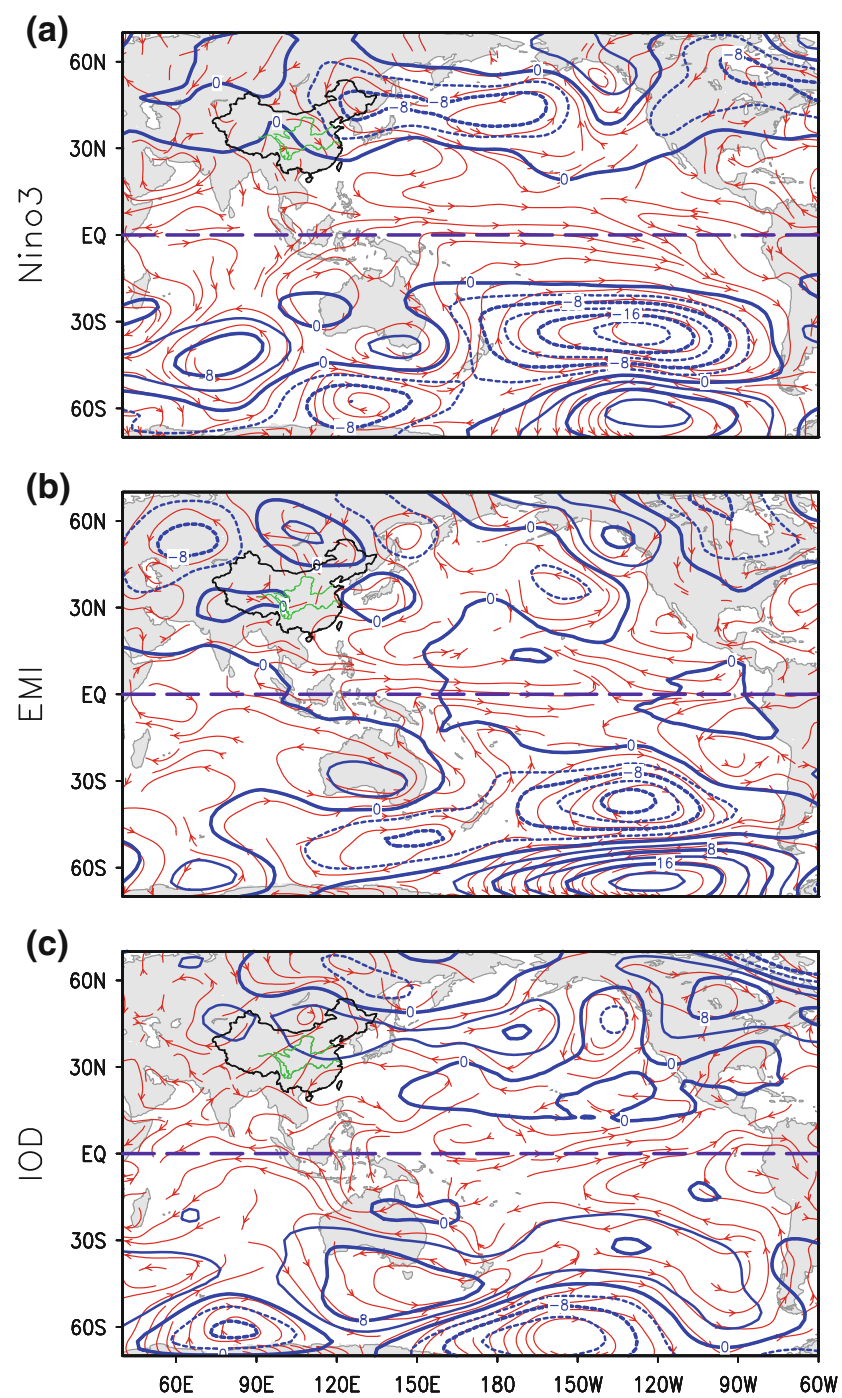

Fig. 5 Partial linear regression patterns of geopotential height anomaly at $500 \mathrm{hPa}$ (blue contour; unit: $\mathrm{m}$ ) and horizontal wind anomaly at $850 \mathrm{hPa}$ (red stream) for a Niño3, b EMI and c IOD

defined as the difference between the area-averaged zonal wind anomalies in the southern box $\left(100^{\circ}-130^{\circ} \mathrm{E}, 5^{\circ}-\right.$ $\left.15^{\circ} \mathrm{N}\right)$ and the northern box $\left(110^{\circ}-140^{\circ} \mathrm{E}, 20^{\circ}-30^{\circ} \mathrm{N}\right)$, as marked in Fig. 6.

The atmospheric circulation patterns at 500 and $850 \mathrm{hPa}$ during El Niño (Fig. 5a) and El Niño Modoki (Fig. 5b) are similar to those with shorter data period shown in Weng et al. (2007). During El Niño (Fig. 5a), a zonally elongated trans-Pacific low band of the $500 \mathrm{hPa}$ geopotential height anomaly in the extratropical Northern Hemisphere covers the region to the north of the Yangtze River, with a low center over northeastern China. This low center is a largescale circulation background for the coldness in most of China (Fig. 4b). It corresponds to wet summers in northeastern China during El Niño (Fig. 4a). The trough over the lower reach of the Yangtze River and the ridge to its west, 

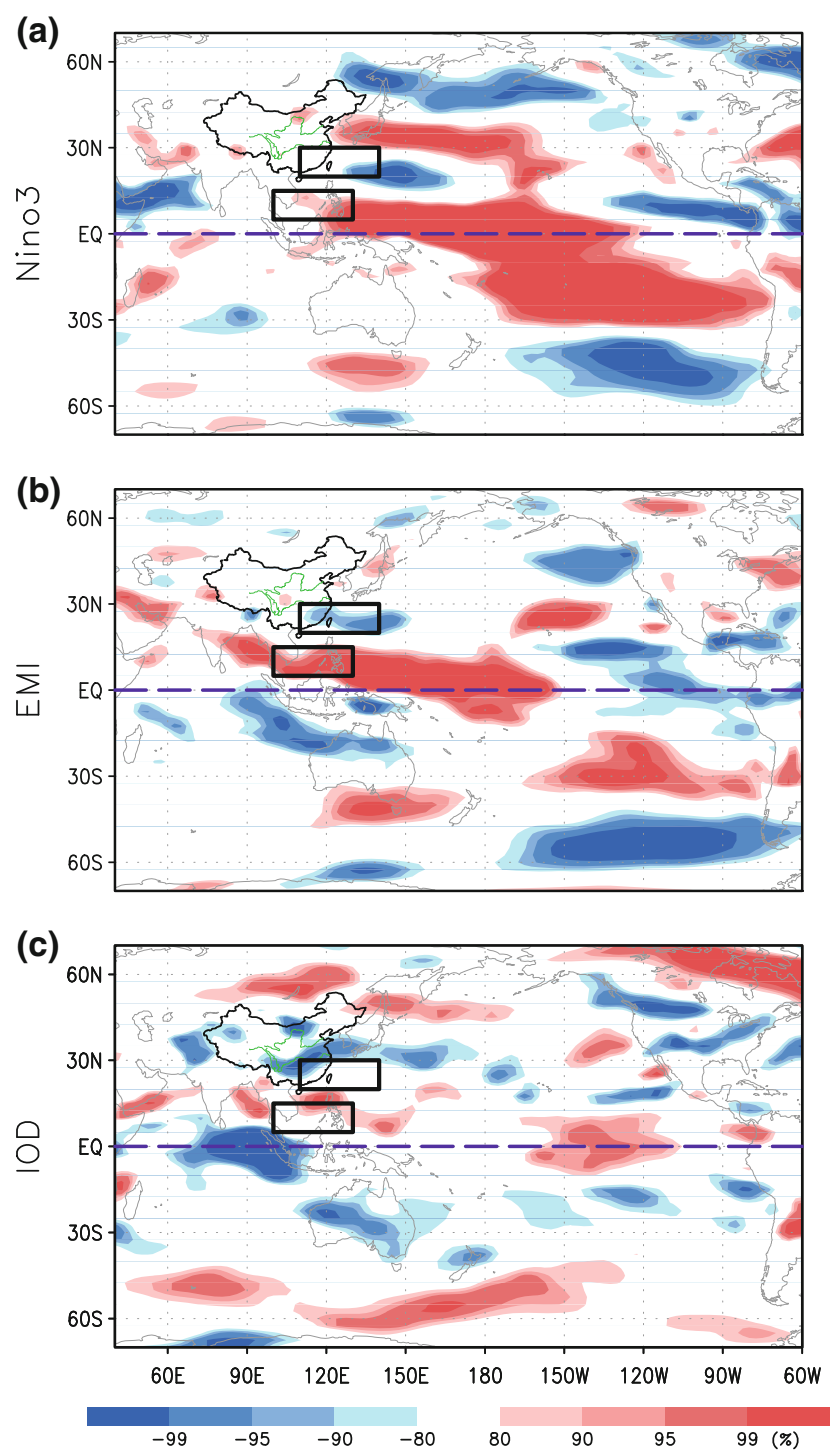

Fig. 6 Partial correlation patterns of zonal wind component at $850 \mathrm{hPa}$ for a Niño3, b EMI, and c IOD. Instead of using coefficients, the significant levels are given for reference. The red (blue) shading shows the westerly (easterly) anomalies. The difference between the area-averaged zonal wind anomaly in the southern and northern black boxes are used to define the WNPSM index (Wang and Fan 1999)

as shown by the zero line of the $500 \mathrm{hPa}$ geopotential height anomaly over China, may be responsible for the wet condition there. At $850 \mathrm{hPa}$, an anomalous anticyclonic system extends northeastward from the South China Sea/ Philippine Sea to the south of Japan. An anomalous trough is to the east of the Philippine Islands so that the strongest tropical westerlies are found to the east of the Maritime Continent. As seen in Fig. 6a, as a part of the meridional wave train initiated from the tropical western Pacific, the pair of the prevailing anomalous westerlies and easterlies are located to the east of the two boxes, where the difference between the westerlies in the south and the easterlies in the north is used to define the WNPSM index. Thus, such a low-level wind system in El Niño summers is likely to result in a weak relationship with the WNPSM.

During El Niño Modoki (Fig. 5b), at $500 \mathrm{hPa}$, two zonal wave trains are aligned in the subtropical and extratropical northern hemisphere. The Mongolian High covers the northwestern part of northeastern China, corresponding to warming there (Fig. 4d). The positive height anomaly center in northwestern Pacific is right over Japan. It implies that the western North Pacific subtropical high has intensified and advanced northwestward near $\left(135^{\circ} \mathrm{E}, 30^{\circ} \mathrm{N}\right)$ from its climatological mean position near $\left(160^{\circ} \mathrm{E}, 25^{\circ} \mathrm{N}\right)$ (Weng et al. 2007), causing warming in the area between the Yangtze River and Huanghe River (Fig. 4d). The convergence zone between the $500 \mathrm{hPa}$ Mongolian High and the western North Pacific subtropical high favors upward movement (or ascending motion) in synoptic-scale systems, corresponding to the wet band from the area to the north of the Huanghe River to the southeastern part of northeastern China (Fig. 4c). At $850 \mathrm{hPa}$ (Fig. 5b), to the south of Japan, there is a zonally aligned monsoon trough extending from the western Pacific/eastern Philippine Sea to the South China Sea, even intruding the Bay of Bengal. Such an anomalous monsoon trough during El Niño Modoki is to the west of the monsoon trough during El Niño (Fig. 5a), corresponding to the heat source in the tropical central Pacific (Fig. 3b), which is also to the west of the heat source during El Niño (Fig. 3a). As shown in Fig. 6b, the westerlies in the southern box and the easterlies in the northern box are stronger than those in the El Niño summers (Fig. 6a). Thus, during El Niño Modoki summers, the WNPSM is very likely stronger than that during El Niño.

During IOD (Fig. 5c), the $500 \mathrm{hPa}$ geopotential height anomaly pattern in extratropical East Eurasia/western North Pacific is almost opposite to that during El Niño (Fig. 5a). The positive geopotential height anomalies are over most of China, resulting in warming there, especially in its northern region (Fig. 4f). The $500 \mathrm{hPa}$ positive geopotential height anomalies over northern China during IOD are stronger than those during El Niño Modoki (Fig. 5b), so are the temperature anomalies (Fig. 4f vs. Fig. 4d). At $850 \mathrm{hPa}$ (Figs. 5c; 6c), the anomalous easterlies between the SSTA dipole in the tropical Indian Ocean are closely related to the wave train originating from the tropical Indian Ocean and extending northeastward along the coastal line of the Eurasian continent. The prevailing tropical westerlies and the easterlies during IOD (Fig. 6c) are shifted northward compared to those during El Niño Modoki (Fig. 6b), resulting in a weaker relationship with the WNPSM than that during El Niño Modoki.

As discussed above, compared with the locations of the strong westerlies in the southern box and the easterlies in the northern box in the western subtropical North Pacific during El Niño Modoki (Fig. 6b), the centers of these wind 
anomalies during El Niño shift eastward in longitude (Fig. 6a), while those during IOD shift northward in latitude (Fig. 6c). Thus, on average, it is expected that the WNPSM index defined by Wang and Fan (1999) is larger during El Niño Modoki than those during El Niño and IOD. The partial correlation coefficients of the time series of the WNPSM index with Niño3, EMI and IOD over the 57 summers are $0.19,0.37$, and 0.17 , respectively. It further confirms that El Niño Modoki is most closely related to the WNPSM among the three tropical phenomena in the linear framework.

As shown by the $850 \mathrm{hPa}$ wind fields in Fig. 5, both the northeasterly winds related to the monsoon trough during El Niño Modoki (Fig. 5b) and the cyclonic systems in the western North Pacific during IOD (Fig. 5c) may bring moist air into southeastern China, causing excess rainfall (Fig. 3c, e). The difference between the climate conditions in the region during the two phenomena is mainly in temperature anomaly field that is largely related to the large-scale mid-level tropospheric circulations. During El Niño Modoki, the $850 \mathrm{hPa}$ monsoon trough that brings excess moist air to southern China is under negative $500 \mathrm{hPa}$ geopotential height anomalies. During IOD, however, the $850 \mathrm{hPa}$ cyclonic system that also brings excess moist air to southern China is under positive $500 \mathrm{hPa}$ geopotential height anomalies. Thus, the monsoon trough during El Niño Modoki is very likely to be deeper and cooler than the cyclonic system during IOD. This may explain why for similar wetness in southern China, it is cool during El Niño Modoki (Fig. 4d)—a negative relationship between rainfall and temperature anomalies, and warm during IOD (Fig. 4f) - a positive relationship between rainfall and temperature anomalies.

After having studied possible links between individual phenomenon and China's summer climate, we can then study what could happen when two or three phenomena coexist, which will be shown in the next section.

\section{Case studies}

Based on the indices shown in Fig. 2 and the partial regression rainfall/temperature anomaly patterns in Fig. 4, we may reconstruct the part of the rainfall/temperature anomalies that are related to one or more of the three tropical phenomena for a given summer. Figure 7 presents SCCF between the observed rainfall/temperature anomaly patterns and the reconstructed ones based on each of the three tropical SSTA indices, as well as their combined effect, for the "all China" in nine selected summers when at least one of the three phenomena can be identified (Fig. 2). Note that the SCCF for each phenomenon in a given summer is not necessarily proportional to the

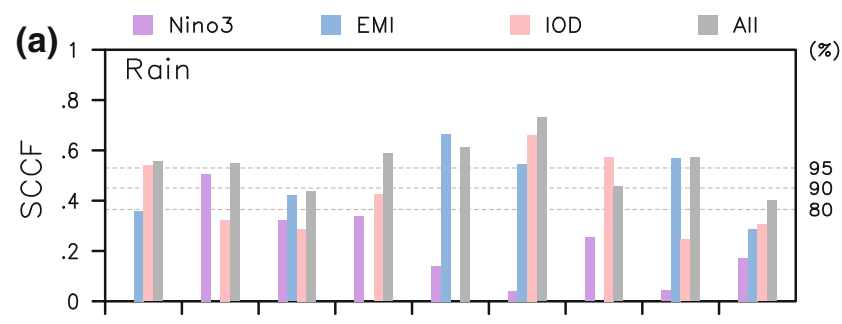

(b) 1

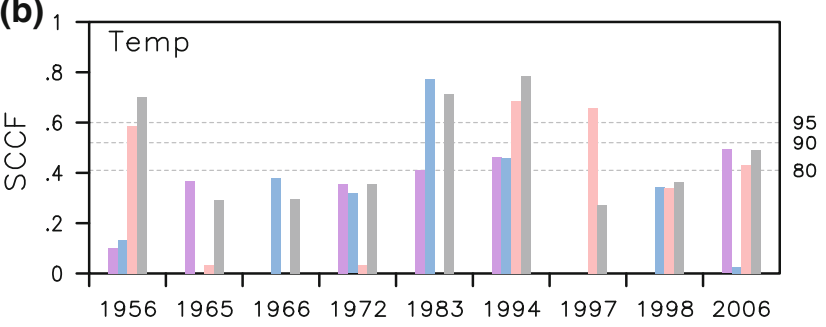

Fig. 7 Spatial correlation coefficient function (SCCF) between observed anomalies and the reconstructed anomalies for the summers of 1956, 1965, 1966, 1972, 1983, 1994, 1997, 1998 and 2006 (all 160 stations are included). a rainfall and $\mathbf{b}$ temperature

magnitude of the corresponding SSTA index. For example, the magnitudes of IOD in 1994 (2.22) and 1983 (1.71) are comparable. However, the IOD in 1994 has the best spatial correlation for both rainfall and temperature compared to other two phenomena and that in 1983 has virtually no correlation. Similar cases could be found in other years or other indices. Such comparisons imply that the "impacts" of an individual tropical phenomenon on China's climate could be greatly influenced by the coexistence of other phenomena in the tropical Indo-Pacific Oceans.

Here we choose the summers of 1994 and 1983 for case studies to show possible impacts by the coexistence of these phenomena on extreme summer climate conditions in China. In both summers, China experienced severe flooding/drought in different regions.

In 1994, the region between the Yangtze River and Huaihe River experienced one of the most severe droughts on record. The drought conditions in several provinces in this region sustained for 40-50 days. Meanwhile the high temperature exceeding $35^{\circ} \mathrm{C}$ sustained for $20-40$ days exacerbated the extremely dry conditions due to lack of rainfall there. ${ }^{7}$ In Anhui Province alone, the drought affected $87 \%$ of its cultivable land, causing 2.35 million tons of crop loss. ${ }^{8}$ In Gansu Province, which is to the west of the YRV, did not receive even a single raindrop in the whole summer. ${ }^{9}$ Meanwhile, severe flooding occurred in southern and northern China. ${ }^{10}$ The Pearl River Valley in

\footnotetext{
${ }^{7}$ http://www.nmc.gov.cn/intro/expert31.html.

${ }^{8}$ http://www.ahsl.gov.cn/fxkh/flood_view.php?id=61.

9 http://www.cjw.com.cn/index/personal/detail/20050513/34311.asp.

${ }^{10}$ http://www.grmc.gov.cn/gdnw/qxzh04.htm.
} 
Fig. 8 Observed (upper panels) and reconstructed (lower panels) rainfall (left panels) and temperature (right panels) for 1994. The reconstruction is based on the partial regression patterns in Fig. 4 and the values of the three indices for 1994 in Fig. 2: Niño3 $=-0.155$, $\mathrm{EMI}=1.91$ and $\mathrm{IOD}=2.22$
1994 JJA
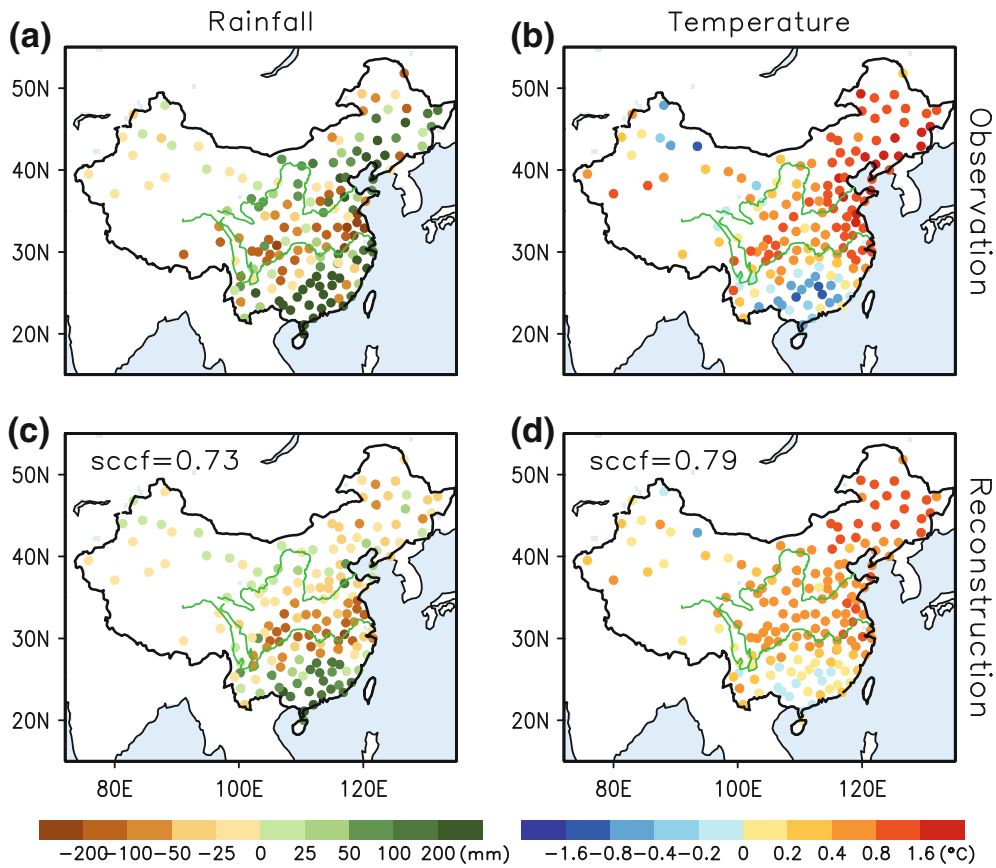

southern China experienced the severest flooding over the past 50 years. In the two southern provinces of Guangdong and Guangxi, the flooding damaged 1.25 million hectares of cultivable land, affected more than 13 millions of people, and caused 63.2 billions (RMB) of direct economic loss. ${ }^{11}$

These severe flooding/drought regions can well be seen in the season-averaged anomaly fields. The observed summer rainfall anomaly pattern for 1994 (Fig. 8a) exhibits mainly wet southern and northern China with a dry YRV in-between. The temperature anomaly pattern (Fig. 8b) shows that most of China is warm, except for southern China where its coldness corresponds to the positive rainfall anomalies.

The reconstructed rainfall and temperature anomaly patterns for 1994 based on the three indices in Fig. 2 and three rainfall and temperature regression patterns in Fig. 4 are given in Figs. 8c and d, respectively. Both the EMI and IOD in 1994 are positively large and the Niño3 is negligible. The reconstructed rainfall anomalies in southern China and the YRV largely reproduce the observed anomalies with similar sign but smaller magnitude. The moist air is transported from the western North Pacific by the enhanced anomalous monsoon trough due to El Niño Modoki (Fig. 5b) as well as by the enhanced anomalous cyclonic flows due to IOD (Fig. 5c). Both events contribute to the severe flooding in the Pearl River and the severe drought in the YRV in the summer of 1994. Due to opposite rainfall anomaly signs in northern China related to

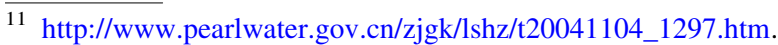

the two phenomena, the El Niño Modoki and IOD in 1994 might have partially cancelled each other's influence on the rainfall anomaly. The reconstructed positive temperature anomalies in the YRV and northern China basically have the same anomaly signs with the observed ones, although with smaller magnitude at most stations (Fig. 8d). In southern China, temperature anomalies at most stations are very weak in both signs. In 1994, the rainfall reconstruction is better for the region in the YRV and to its south, and the temperature reconstruction is better for the region in the YRV and to its north.

In 1983, the regions with severe flooding and drought are very different from those in 1994. The mid- and lowerreaches of the Yangtze River experienced severe flooding, affecting more than 3 million hectares of cultivable land in four related provinces. ${ }^{12}$ Meantime, severe droughts occurred in southern and northern China. Some areas of Shandong Province in northern China experienced one of the severest droughts over the past one hundred years. ${ }^{13}$

The observed rainfall anomaly pattern in 1983 (Fig. 9a) exhibits a more distinguished interwoven feature than that in 1994 (Fig. 8a). It consists of dry regions in southern and northern China and wet regions in the YRV and northeastern China. The observed temperature anomaly pattern in 1983 (Fig. 9b) also shows an interwoven feature having warm southern and northern China and cold YRV and northeastern China. The rainfall and temperature anomalies in most of China have a good negative correspondence.

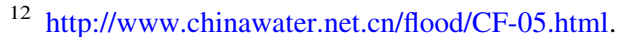

13 http://www.infobase.gov.cn/intro/fzlt/63.htm.
} 
Fig. 9 Same as Fig. 8 except for 1983 when Niño3 = 1.72,

$\mathrm{EMI}=-3.40$, and $\mathrm{IOD}=1.71$

\section{JJA}
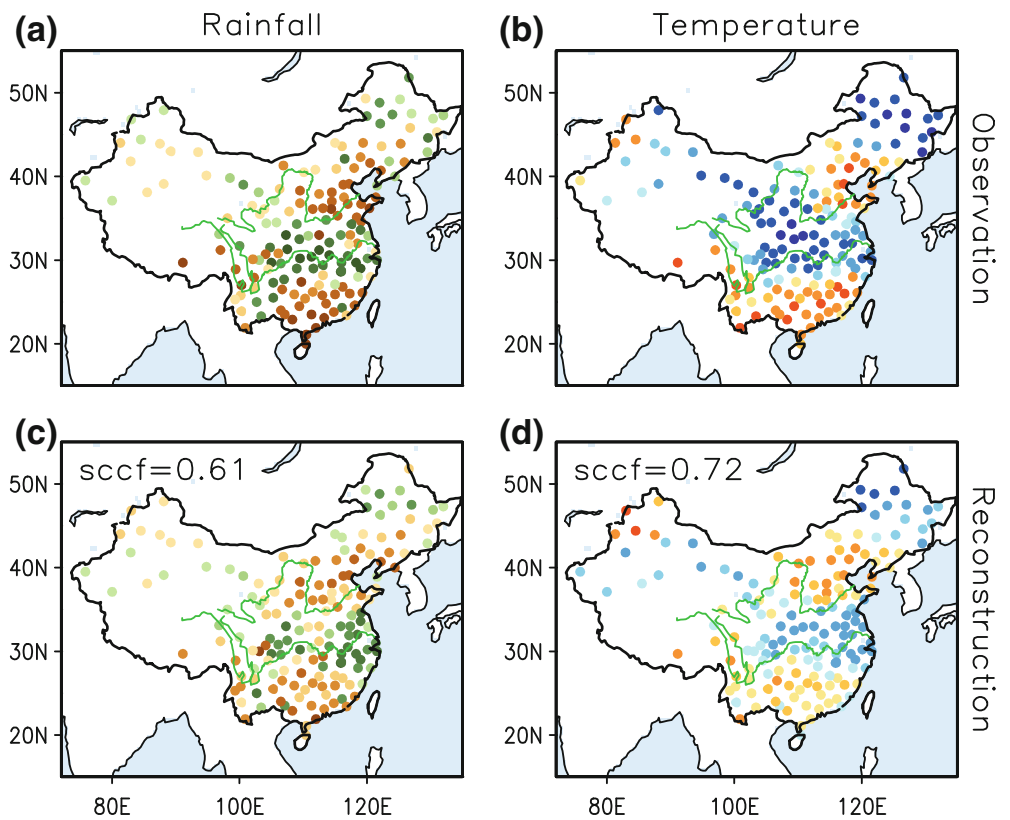

$\begin{array}{llllll}-1.6-0.8-0.4-0.2 & 0 & 0.2 & 0.4 & 0.8 & 1.6\left({ }^{\circ} \mathrm{C}\right)\end{array}$
The reconstructed anomaly patterns for both rainfall (Fig. 9c) and temperature (Fig. 9d) in 1983 look very similar to their observational counterparts but smaller in magnitude. The EMI is negative with the largest magnitude in the data period, and both Niño3 and IOD are positive with moderate magnitudes. Thus, in that summer, all the three phenomena might have influenced the rainfall and temperature anomalies in China. The combined negative EMI and positive Niño3 produce the wet/dry and cold/warm bands in China. The wet and cold summer in northeastern China, considered by previous authors to be related to El Niño event (e.g., Wang and Wu 1997), is enhanced by a strong negative phase of El Niño Modoki. Their combined cold effects greatly suppress the warm influence from the moderate IOD. In southern China, the anomalous cyclonic circulation due to IOD that supplies moist air from the western North Pacific to southern China was suppressed by the anomalous anticyclonic circulation related to the strong negative phase of El Niño Modoki. As a result, abundant moist air is transported from the Bay of Bengal to the YRV by the southwesterlies over the western edge of the anomalous anticyclonic system, with an opposite flow direction to the $850 \mathrm{hPa}$ flow shown in Fig. $5 \mathrm{~b}$, causing drought in southern China and the flooding in the YRV.

The values of $P$, defined in (2), is calculated for the allChina in 1994 and 1983 (see Table 1) when one or all of the three phenomena exist. The combined effects of the three phenomena explain about 36\% (70\%) for the rainfall (temperature) anomalies in 1994 and 39\% (47\%) in 1983 for the all-China, respectively. These are quite large
Table 1 The explained rainfall and temperature variance, $P$ (in percentage), by Niño3, EMI and IOD and their combined effects on rainfall and temperature for the all-China in the summers of 1994 and 1993

\begin{tabular}{lcccrl}
\hline Variable & Year & Niño3 & EMI & IOD & Combined \\
\hline Rain & 1994 & 1 & 17 & 22 & 36 \\
Rain & 1983 & 2 & 43 & 0 & 39 \\
Temp. & 1994 & 3 & 22 & 56 & 70 \\
Temp. & 1983 & 21 & 50 & 0 & 47 \\
\hline
\end{tabular}

portions of the total rainfall and temperature variances that can be explained by the SSTA patterns in the tropical IndoPacific Oceans.

\section{Discussion and concluding remarks}

This study investigates possible links between the SSTA patterns in the Indo-Pacific Oceans and the summer rainfall/temperature anomalies in China during the summers of 1951-2007. The teleconnection paths are through the related anomalous mid- and low-level tropospheric circulations over this oceanic region and East Eurasia, including the WNPSM. The summer rainfall/temperature anomalies in China, which are related to the three phenomena in the Indo-Pacific Oceans (El Niño, El Niño Modoki and IOD), are portioned by applying the partial linear correlation/ regression analysis based on the three SSTA indices (Niño3, EMI and IOD). 
The three tropical phenomena are shown to exert their impacts on the China summer climate through different paths regarding rainfall and temperature anomalies. For rainfall anomalies, the influence path is largely through the low-level tropospheric circulation, including the WNPSM, which influences the rainfall more in the YRV and southern China than northern China. For temperature anomalies, the influence path is largely through the mid-level tropospheric circulation, especially the western North Pacific subtropical high, which influences the temperature more in the YRV and northern China than southern China. In general, there is a good negative correlation between summer rainfall and temperature anomalies in China. It is because the clouds in wet regions reduce the incoming solar radiation resulting in lower surface temperature, and dry conditions under subtropical high system favors more sunshine resulting in higher surface temperature. Exceptions may also occur due to anomalous mid- and low-level tropospheric circulations, such as the condition in southern China when a strong IOD occurs as the only phenomenon in the tropical Indo-Pacific Oceans.

When only one of the phenomena develops, the location and intensity of the individual phenomenon in the IndoPacific Oceans excite different wave trains in the mid- and low-level troposphere over the region. The wave train during El Niño is to the east of the one during El Niño Modoki, mainly due to their different locations of the warm SST center along the equator. During IOD, the wave train is aligned southwest-northeast along the coastal line of the Eurasian continent. Different horizontal and meridional locations of the three wave trains exert different impacts on China's climate. These wave trains in the low-level troposphere show that El Niño Modoki has the best relationship with the WNPSM compared to El Niño and IOD.

In the event of simultaneous occurrence of two or three phenomena (with either positive or negative phases), the combined explained rainfall (temperature) variance related to these phenomena is not simply a sum of the explained rainfall (temperature) variance related to each individual phenomenon. They may enhance or weaken each other's influence, depending on the magnitude and the sign of their indices and rainfall/temperature anomaly signs they may link to. Thus, to make an empirical prediction about climate influenced by an individual tropical phenomenon while other tropical phenomena coexist is not easy. Such a situation can be clearly seen in the two cases of 1994 and 1983 discussed in Sect. 5.

The climate variability and its lagged response to the tropical SST forcing on the sub-seasonal timescales, which may be important to extreme climate events, cannot be discerned in this study due to the limitation of using the summer seasonal data. Further analyses focusing on the summer climate, by using monthly data instead of seasonal data (Taschetto et al. 2009), in different regions of China influenced by these SSTA patterns are encouraged.

All the three phenomena in the Indo-Pacific Oceans discussed here are mainly related to the zonal SSTA gradients in this tropical oceanic region. It is the zonal SSTA gradients that force characteristic Walker cells in the tropical Indo-Pacific Oceans during these phenomena, which in turn force characteristic meridional circulations that influence regional climate in China. Whether considering the zonal SSTA gradients in the tropical Pacific is also the main difference between the definition of El Niño Modoki and other definitions regarding the tropical central warming based on area-mean SSTA, such as the CP type of ENSO (Yu and Kao 2007; Kao and Yu 2009) and the WP type of ENSO (Kug et al. (2009) mentioned in the introduction.

Other SSTA patterns in the broad tropical Indo-Pacific Oceans such as the basin-wide warming/cooling in either tropical Pacific or Indian Ocean, or both, which do not represent SSTA gradients as those discussed here, may also exert important influence on summer climate in China by changing the amount of moisture supply to China.

The vital results presented here account for a modest spur to induce more studies to come forward with valuable contributions to understand possible influence of the tropical Indo-Pacific Oceans on anomalous summer climate in China. Such studies will help improve prediction of extreme climate events in different regions of China once any of these phenomena in the tropical Indo-Pacific Oceans for a summer season, not for the preceding winter season, is first predicted.

Acknowledgments We are thankful to Shaowu Wang, Jianbin Huang and Huanzhu Liu for providing rainfall and temperature data in China, to Liang Guo and Jun Wang for their kind technical help. The helpful comments and suggestions by the two anonymous reviewers are greatly appreciated. This work was jointly supported by the National Key Basic Research and Development Project of China under grant No. 2006CB403607, CAS project under grant KZCX2YW-Q11-01, and the Natural Science Foundation of China under grants 40821092, 40875034, and 40523001. HYW was mainly supported by the LASG State Key Laboratory Special Fund in China, and partially supported by the FRCGC/JAMSTEC in Japan.

Open Access This article is distributed under the terms of the Creative Commons Attribution Noncommercial License which permits any noncommercial use, distribution, and reproduction in any medium, provided the original author(s) and source are credited.

\section{References}

Ashok K, Behera SK, Rao SA, Weng HY, Yamagata T (2007) El Niño Modoki and its teleconnection. J Geophys Res 112:C11007. doi:10.1029/2006JC003798

Ashok K, Iizuka S, Rao SA, Saji NH, Lee WJ (2009) Processes and boreal summer impacts of the 2004 El Niño Modoki: 
an AGCM study. Geophys Res Lett 36:L04703. doi:10.1029/ 2008GL036313

Behera SK, Krishnan R, Yamagata T (1999) Unusual oceanatmosphere conditions in the tropical Indian Ocean during 1994. Geophy Res Lett 26:3001-3004

Behera SK, Luo JJ, Mason S, Rao SA, Sakuma H, Yamagata T (2006) A CGCM study on the interaction between IOD and ENSO. J Clim 19:1688-1705

Behera SK, Luo JJ, Yamagata T (2008) Unusual IOD event of 2007. Geophys Res Lett 35:L14811. doi:10.1029/2008GL034122

Bjerknes J (1969) Atmospheric teleconnections from the equatorial Pacific. Mon Weather Rev 97:163-172

Bretherton CS, Widmann M, Dymnikov VP, Wallace JM, Bladé I (1999) The effective number of spatial degrees of freedom of a time-varying field. J Clim 12:1990-2009

Chan JCL, Zhou W (2005) PDO, ENSO and the summer monsoon rainfall over South China. Geophys Res Lett 32:L08810. doi: 10.1029/2004GL022015

Chang CP, Zhang Y, Li T (2000) Interannual and interdecadal variations of the East Asian summer monsoon and tropical Pacific SSTs. Part I: roles of the subtropical ridge. J Clim 13:4310-4325

Chang CWJ, Hsu HH, Wu CR, Shen WJ (2008) Interannual mode of sea level in the Southern China Sea and the roles of El Niño and El Niño Modoki. Geophys Res Lett 35:L03601. doi:10.1029/ 2007GL032562

Ding YH, Chan JCL (2005) The East Asian summer monsoon: an overview. Meteorol Atmos Phys 89:117-142

Gao H, Wang Y, He J (2006) Weakening significance of ENSO as a predictor of summer precipitation in China. Geophys Res Lett 33:L09807. doi:10.1029/2005GL025511

Guan Z, Yamagata T (2003) The unusual summer of 1994 in East Asia: IOD teleconnections. Geophys Res Lett 30:1544. doi: 10.1029/2002GL016831

Guan Z, Ashok K, Yamagata T (2003) Summertime response of the tropical atmosphere to the Indian Ocean dipole sea surface temperature anomalies. J Meteor Soc Jpn 81:533-561

Huang R, Wu Y (1989) The influence of ENSO on the summer climate change in China and its mechanism. Adv Atmos Sci 6:21-32

Ju J, Slingo JM (1995) The Asian summer monsoon and ENSO. Q J R Meteorol Soc 121:1133-1162

Kalnay E et al (1996) The NCEP/NCAR 40-year reanalysis project. Bull Am Meteorol Soc 77:437-471

Kao HY, Yu JY (2009) Contrasting eastern-Pacific and central-Pacific types of ENSO. J Clim 22:615-632. doi:10.1175/2008JCLI2309.1

Kim HM, Webster JW, Curry JA (2009) Impact of shifting patterns of Pacific Ocean warming on North Atlantic tropical cyclones. Science 325:77. doi:10.1126/science. 1174062

Kug JS, Jin FF, An SL (2009) Two types of El Niño events: Cold tongue El Niño and warm pool El Niño. J Clim 22:1499-1515

Larkin NK, Harrison DE (2005) On the definition of El Niño and associated seasonal average U.S. weather anomalies. Geophys Res Lett 32:L13705. doi:10.1029/2005GL022738

Lau KM, Weng HY (2001) Coherent modes of global SST and summer rainfall over China: an assessment of the regional impacts of the 1997-98 El Niño. J Clim 14:1294-1308

Li C, Mu M (2001) The influence of the Indian Ocean dipole on atmospheric circulation and climate. Adv Atmos Sci 18:831-843

Lindzen RS, Nigam S (1987) On the role of sea surface temperature gradients in forcing low-level winds and convergence in the tropics. J Atmos Sci 44:2418-2436

Liu YM, Chan JCL, Mao JY, Wu GX (2002) The role of Bay of Bengal convection in the onset of the 1998 South China Sea Summer Monsoon. Mon Weather Rev 130:2731-2744
Rasmusson EM, Carpenter TH (1982) Variation in tropical sea surface temperature and surface wind fields associated with the Southern Oscillation/El Niño. Mon Weather Rev 110:354384

Rayner NA, Parker DE, Horton EB, Folland CK, Alexander LV, Rowell DP, Kent EC, Kaplan A (2003) Global analyses of SST, sea ice and night marine air temperature since the late nineteenth century. J Geophys Res 108. doi:10.1029/2002JD002670

Saji NH, Goswami BN, Vinayachandran PN, Yamagata T (1999) A dipole mode in the tropical Indian Ocean. Nature 401:360-363

Tao S, Chen L (1987) A review of recent research on the East Asian summer monsoon in China, review in monsoon meteorology. Oxford University Press, Oxford, pp 60-92

Taschetto AS, England MH (2009) El Niño Modoki impacts on Australian rainfall. J Clim. doi: 10.1175/2008JCLI2589.1

Taschetto AS, Ummenhofer CC, Gupta AS, England MH (2009) The effect of anomalous warming in the central Pacific on the Australian monsoon. Geophys Res Lett 36:L12704. doi: 10.1029/2009GL038416

Tozuka T, Luo JJ, Masson S, Yamagata T (2008) Tropical Indian Ocean variability revealed by self-organizing maps. Clim Dyn 31:333-343

Trenberth KE (1997) The definition of El Niño. Bull Am Meteorol Soc 78:2771-2777

Trenberth KE, Caron JM, Stepaniak DP, Worley S (2002) Evolution and El Niño-Southern Oscillation and global atmospheric surface temperatures. J Geophys Res (107D8), 4065. doi: 10.1029/ 2000JD000298

Wallace JM, Rasmusson EM, Mitchell TP, Kousky VE, Sarachik ES, von Storch H (1998) On the structure and evolution of ENSO related climate variability in the tropical Pacific: lessons from TOGA. J Geophys Res 103(C7):14241-14260. doi:10.1029/ 97JC02905

Wang B, Fan Z (1999) Choice of south Asian summer monsoon indices. Bull Am Meteorol Soc 80:629-638

Wang G, Hendon HH (2007) Sensitivity of Australian rainfall to inter-El Niño variations. J Clim 20:4211-4226

Wang JF, Wu GX (1997) Evolution and characteristics of the persistent cold summer in Northeast China. Chin J Atmos Sci 21:295-305 (in Chinese)

Wang Y, Yasunari T (1994) A diagnostic analysis of the wave train propagating from high-latitudes to low-latitudes in early summer. J Meteorol Soc Japan 72:269-279

Wang B, Wu R, Li T (2003) Atmosphere-warm ocean interaction and its impacts on Asian-Australian monsoon variation. J Clim 16:1195-1211

Weng HY, Sumi A, Takayabu YN, Kimoto M, Li C (2004) Interannual-interdecadal variation in large-scale atmospheric circulation and extremely wet and dry summers in China/Japan during 1951-2000. Part I: spatial patterns. J Meteorol Soc Jpn 82:775-788

Weng HY, Ashok K, Behera S, Rao AS, Yamagata T (2007) Impacts of recent El Niño Modoki on dry/wet conditions in the Pacific Rim during boreal summer. Clim Dyn 29:113-129. doi: 10.1007/s00382-007-0234-0

Weng HY, Behera SK, Yamagata T (2009) Anomalous winter climate conditions in the Pacific Rim during recent El Niño Modoki and El Niño events. Clim Dyn 32:663-674. doi:10.1007/s00382008-0394-6

Wu GX, Liu HZ (1992) Atmospheric precipitation in response to equatorial and tropical sea surface temperature anomaly. J Atmos Sci 49:2236-2255

Wu GX, Liu HZ (1995) Neighborhood response of rainfall to tropical sea surface temperature anomalies. Part I. Numerical experiment. Chin J Atmos Sci 19:279-292 
Wu GX, Meng W (1998) Gearing between the Indo-Monsoon circulation/Pacific-Walker circulation and ENSO, Part I: Data analysis. Chin J Atmos Sci 22:470-480

Wu GX, Liu P, Liu YM, Li WP (2000) Impacts of the sea surface temperature anomaly in the Indian Ocean on the subtropical anticyclone over the western Pacific-two stage thermal adaptation in the atmosphere. Acta Meteorol Sin 58:513-522

Xiao Z, Yan H, Li C (2002) Relationship between dipole oscillation of SSTA of Indian Ocean region and precipitation and temperature in China. J Trop Meteorol 8:121-131
Yamagata T, Behera SK, Luo JJ, Masson S, Jury MR, Rao SA (2004) The coupled ocean-atmosphere variability in the tropical Indian Ocean. Earth's climate: the ocean-atmosphere interaction. Geophysical Monograph 147:189-211

Yu JY, Kao HK (2007) Decadal changes of ENSO persistence barrier in SST and ocean heat content indices: 1958-2001. J Geophys Res 112:D13106. doi:10.1029/2006JD007654

Zhang RH, Sumi A, Kimoto M (1999) A diagnostic study of the impact of El Niño on the precipitation in China. Adv Atmos Sci 16:229-241 